\title{
RENTABILIDADE DA TANGERINEIRA 'PONKAN' SUBMETIDA AO RALEIO QUÍMICO COMPARADA COM AO MANEJO CONVENCIONAL ${ }^{1}$
}

\author{
MARIA DO CÉU MONTEIRO CRUZ², RODRIGO AMATO MOREIRA², \\ NEIMAR ARCANJO DE ARAÚJO ${ }^{4}$
}

RESUMO - A pesquisa foi conduzida em um pomar comercial, localizado no município de Perdões, região sul de Minas Gerais, com o objetivo de analisar e comparar a rentabilidade da produção da tangerineira 'Ponkan' (Citrus reticulata Blanco) submetida ao raleio químico com o manejo convencional. Para se montar a matriz de coeficientes técnicos dos custos de produção e os indicadores de rentabilidade da cultura, os dados foram obtidos com os produtores da região e baseados em trabalho de pesquisa realizado no pomar, no período de dezembro de 2006 a julho de 2008. Foram utilizadas plantas com dez anos de enxertadas sobre limoeiro 'Cravo' (Citrus limonia Osbeck). No primeiro ano, o raleio químico foi realizado com aplicação de Ethephon na concentração de $600 \mathrm{mg} \mathrm{L}^{-1}$,e por ocasião da colheita foi avaliado o rendimento da produção nas plantas submetidas ao raleio químico e ao manejo convencional. No segundo ano, foi determinada a alternância de produção e a produtividade. A prática do raleio químico proporcionou maior rentabilidade, em termos de produtividade da tangerina 'Ponkan', que o manejo convencional, sem a adoção do raleio.

Termos para indexação: Citrus reticulata, Ethephon, rendimento, manejo.

\section{'PONKAN' MANDARIN PROFITABILITY UNDER FRUIT THINNING}

\begin{abstract}
The research was developed in a commercial orchard, in Perdões, southern Minas Gerais state, Brazil, aiming to analyze and compare the profitability of the 'Ponkan' mandarin (Citrus reticulata Blanco) production, submitted to both chemical thinning and conventional cultivation. To estimate technical coefficients of production costs and profitability indicators of culture, data were surveyed from regional producers and based in experimental work, carried out in the orchard, from December, 2006 to July, 2008. Ten-year-old plants grafted on 'Rangpur' lime (Citrus limonia Osbeck),,were used. In the first year, the chemical thinning was performed using Ethephon at the concentration of $600 \mathrm{mg} \mathrm{L}^{-1}$ and at harvest the crop production was estimated, in plants both under chemical thinning and under conventional cultivation. In the second year the alternate bearing and the productivity were evaluated. The chemical thinning practice provided higher profitability, in terms of productivity of 'Ponkan' mandarin than the conventional management without the adoption of the thinning.
\end{abstract}

Index terms - Citrus reticulata, Ethephon, yield, management.

\section{INTRODUÇÃO}

O raleio químico, com as aplicações exógenas de fitorreguladores, é utilizado em tangerineira 'Ponkan' para minimizar a alternância de produção, caracterizada pela produção excessiva, intercalada com ano de baixa produção, em decorrência da ausência de produção por parte das plantas do pomar. Isso é um problema na cultura da tangerineira 'Ponkan', pois torna a atividade pouco rentável. Além disso, essa prática tem sido feita para reduzir a quantidade de frutas na planta e melhorar a qualidade, porque, nos anos de maior produção, as frutas são pequenas e de baixa qualidade, o que dificulta sua comercialização, em função da exigência do mercado de fruta de mesa, que prefere frutas de tamanhos maiores.

Para a tangerineira 'Ponkan', o tamanho da

\footnotetext{
${ }^{1}$ Trabalho Sinfruit 027 - Simpósio Internacional de Fruticultura - Avanços na Fruticultura (17 a 21 Outubro)

${ }^{2}$ Pós-Doutorado em Fitotecnia, Profa. do Departamento de Agricultura da UFVJM, Rodovia MGT 367- Km 583, nº 5.000 CEP 39100 000 Diamantina, MG. E-mail: mariceu@ufvjm.edu.br

${ }^{3}$ Doutorando em Fitotecnia, UFLA. Cx. Postal 3037, Lavras-MG. CEP 37200-000. Bolsista da CAPES.

E-mail: amatomoreira@yahoo.com.br

${ }^{4}$ Graduando do Curso de Agronomia, UFLA. Cx. Postal 3037, Lavras-MG. CEP 37200-000. E-mail: neimararcanjo@yahoo.com.br
} 
fruta é importante, pois, além de influenciar na sua comercialização e aceitação no mercado determina o rendimento produtivo. Para alterar as características relacionadas ao tamanho da fruta, é necessária a redução no número de frutas por planta, mediante a realização do raleio, o que tem contribuído para aumentar o rendimento da produção comercial (CRUZ et al., 2011).

$\mathrm{O}$ efeito do raleio sobre crescimento das frutas é relacionado por diversas evidências, incluindo o aumento da relação fonte-dreno, porque o crescimento de frutas depende da taxa de suprimento de fotoassimilados provenientes das fontes (GARCÍA-LUÍS et al., 2002).

Visando à reduzir custos, a melhorar a qualidade e a agregar valor, o raleio químico pode ser uma alternativa direcionada a mercados diferenciados, tais como o mercado de fruta de mesa. Dessa forma, a avaliação da rentabilidade da produção do pomar de tangerineira 'Ponkan' submetida ao raleio químico, comparativamente ao manejo convencional, pode constituir-se em importante fonte de informação que permitirá ao produtor avaliar a viabilidade da adoção da prática de manejo em seu pomar.

Diante do exposto este trabalho foi realizado com o objetivo de analisar e comparar rentabilidade da produção da tangerineira 'Ponkan' (Citrus reticulata Blanco) submetida ao raleio químico cultivo convencional.

\section{MATERIAL E MÉTODOS}

A pesquisa foi desenvolvida em um pomar comercial, não irrigado, localizado em Perdões, $21^{\circ}$ 05’27 “(S) e $45^{\circ} 05^{\prime} 27^{\prime}$ ” (W), sul de Minas Gerais, Brasil. A altitude média da região é de 826 metros. O clima é do tipo Cwbcaracterizado por invernos quentes e verões úmidos, secos e frios de acordo com a classificação de Köeppen. A precipitação anual é de $1.240 \mathrm{~mm}$, e o período chuvoso está compreendido de outubro a março, e a temperatura média, em torno de $20,8^{\circ} \mathrm{C}$.

Foram utilizadas tangerineiras 'Ponkan' (Citrus reticulata Blanco cv. Ponkan) enxertadas sobre limoeiro 'Cravo' (C. limonia Osbeck) e plantadas no espaçamento de $6 \mathrm{~m}$ entre linhas e $3 \mathrm{~m}$ entre plantas, com dez anos de idade.

Em ambos os sistemas de manejo, com e sem raleio químico, as adubações das plantas foram realizadas de acordo com análises de solo e foliar, os tratos culturais e o controle de pragas foram realizados conforme as recomendações técnicas para a cultura.
Para promover o raleio químico, em 2007, as plantas foram selecionadas quanto ao potencial produtivo, de forma que todas as plantas submetidas aos tratamentos apresentassem quantidade significativa de frutas.

As plantas foram pulverizadas com o produto comercial ZAZ ${ }^{\circledR}$, concentrado solúvel, 480 $\mathrm{g} \mathrm{L}^{-1}$ de ácido 2-cloroetilfosfônico (Ethephon) com a concentração de $600 \mathrm{mg} \mathrm{L}^{-1}$. As aplicações foram realizadas em toda a extensão da copal (interna e externa) para promover o raleio uniforme após o período de queda fisiológica dos frutilhos, no mês de janeiro.

Em 2008, não foi realizada a aplicação do Ethephon para se observar o efeito do raleio químico realizado no anterior sobre a ocorrência da alternância de produção e a produtividade.

Determinaram-se a produção por planta (caixas de $22 \mathrm{~kg}$ ), produtividade por área (produção por planta $\mathrm{x}$ número de plantas por área de acordo com o espaçamento). O rendimento da produção foi determinado considerando as características de tamanho da fruta, de acordo com os critérios estabelecidos pelo CEAGESP (2000), e o padrão requerido pelo mercado de destino. Foram consideradas dentro desses padrões as frutas acima de 58 e $60 \mathrm{~mm}$ para os diâmetros, longitudinal e transversal, respectivamente.

A análise da rentabilidade foi realizada de forma simplificada considerando os custos produção do pomar já implantado com a produção estável. Este tipo de análiseé utilizada para verificar se os recursos empregados em um processo de produção estão sendo remunerados, possibilitando também verificar como está a rentabilidade da atividade.

Os dados dos custos de produção de 1,0 ha de tangerineira utilizados foram obtidos diretamente do experimento acima citado e complementados por informações levantadas junto a produtores e técnicos da região.

A metodologia para o cálculo de custo de produção utilizada foi adaptada do Instituto de Economia Agrícola (IEA), descrita por Matsunaga et al. (1976). Os custos de produção apresentados basearam-se no custo operacional efetivo (COE), que são as despesas efetuadas com mão de obra, operações de máquinas/equipamentos e materiais consumidos ao longo do processo produtivo e no custo operacional total (COT). O custo de mão de obra foi expresso pelo valor da diária paga aos trabalhadores rurais, e o das operações mecanizadas, pelo valor pago por hora/máquina de um trator médio $(75 \mathrm{cv})$, praticados na região.

Para a determinação dos custos operacionais 
totais (COT) da tangerineira, com e sem a adoção do raleio de frutas, somaram-se os custos variáveis (COE) compostos por insumos, tratos culturais e as despesas fixas. A depreciação de máquinas e equipamentos não foi considerada, por utilizar o preço de alocação, prática adotada na região. Para o custo operacional total (COT), foi evitada a inclusão de custos dos fatores terra e capital e empresário em razão da subjetividade com que podem ser estimados. Entretanto, subentende-se que parte da renda será utilizada para remunerar o custo com a gestão do empreendimento.

A receita bruta foi estimada a partir do total de caixas colhidas, multiplicada pelo preço de comercialização em cada ano avaliado, visto que as despesas com a colheita (mão de obra), transporte, embalagens (caixas de colheita) são custeadas pelo comprador.

A análise da rentabilidade da cultura constitui-se na diferença entre a receita bruta e o custo operacional total (COT) por hectare, e mede rentabilidade da atividade no curto prazo, para cada ano agrícola.

\section{RESULTADOS E DISCUSSÃO}

O custo operacional total do primeiro ano, nas plantas que foram submetidas ao raleio químico, foi de $\mathrm{R} \$ 4.217,75$ por ha (Tabela 1), e no sistema de manejo sem a prática do raleio químico foi de $\mathrm{R} \$$ $3.995,75$ por ha (Tabela 2). A diferença observada de $\mathrm{R} \$ 222,00$ foi referente às despesas com a compra do fitorregulador para realizar o raleio, Ethephon e a mão de obra para aplicação. Este valor representa 5,26\% do custo operacional efetivo. No segundo ano, os custos operacionais foram semelhantes em ambos os sistemas de manejo, R $\$ 4.224,00$, pois não foi realizado o raleio das frutas, com o intuito de avaliar o comportamento produtivo no ano seguinte ao raleio.

A produtividade obtida no primeiro ano foi de 2.107 caixas de $22 \mathrm{~kg} \mathrm{ha}^{-1}$ nas plantas submetidas ao raleio químico (Tabela 1), e nas naquelas sob manejo convencional a produtividade foi de 1.175 caixas de $22 \mathrm{~kg} \mathrm{ha}^{-1}$ (Tabela 2), o que correspondeu à produtividade de 55,76\% maior com a prática do raleio. Esta diferença observada no rendimento da produção, em 2007, pode ser atribuída à desuniformidade no tamanho das frutas, nas plantas que não foram submetidas ao raleio, sendo a maioria deles classificado como de produção não comercial.

A não comercialização de frutas de menor tamanho, no caso da tangerineira 'Ponkan' está associada à preferência do mercado consumidor por frutas de maior tamanho, o que gera diferenças no preço, no momento da comercialização e quando comparado ao preço das frutas menores geralmente o rendimento não é suficiente para custear as despesas com seleção e frete (GUARDIOLA; GARCÍA-LUIS, 2000).

A realização de raleio em tangerineiras 'Ponkan' tem demonstrado que, apesar da menor quantidade de frutas por planta, o rendimento da produção comercial tem sido maior em decorrência da melhor uniformidade no tamanho, nas frutas remanescentes (CRUZ et al., 2011).

Na avaliação realizada na safra de 2008, os resultados foram semelhantes, com maior rendimento nas plantas que foram submetidas ao raleio químico no ano anterior. Nestas plantas, a produtividade foi de 2.414 caixas de $22 \mathrm{~kg} \mathrm{ha}^{-1}$,com incremento de 1.356 caixas em relação às plantas que não foram submetidas ao raleio, que produziram $1.057,28$ caixas de $22 \mathrm{~kg} \mathrm{ha}^{-1}$. Este resultado evidencia que o raleio favoreceu a redução da alternância de produção no ano subsequente à sua aplicação e, por isso, mesmo sem a realização do raleio, a produção ocorreu de maneira uniforme.

A diferença de produção observada em 2008 nas plantas submetidas ao raleio químico, em 2007, comprova que excesso de frutificação causa o esgotamento de reservas nas plantas e influencia na produção, no ano seguinte, devido à alta quantidade de carboidratos utilizada (GOLDSCHMIDT, 1999). Com relação à receita, verificou-se que a realização do raleio proporcionou ao produtor maior rentabilidade, em termos de produtividade, e com baixo custo operacional. Analisando o resultado nos dois anos de produção as plantas submetidas ao raleio proporcionaram receitas de $\mathrm{R} \$ 14.116,90 \mathrm{em}$ 2007 e R \$ 15.932,40 em 2008, o que representou rentabilidade de $\mathrm{R} \$ 9.899,15$ e $\mathrm{R} \$ 11.708,40$, respectivamente (Tabela 1 ), enquanto sem a adoção da prática do raleio as receitas alcançadas foram de R\$ 7.872,5 em 2007 e R \$ 6.978,05 em 2008 , com retorno de $\mathrm{R} \$ 3.876,75$ e $\mathrm{R} \$ 2.754,05$, respectivamente (Tabela 2). Esta diferença representa incrementos de $\mathrm{R} \$ 6.022,40$ no primeiro ano e de $\mathrm{R} \$$ $8.954,35$ no segundo ano.

Comprovou-se maior índice de rentabilidade com a adoção da prática do raleio químico, de 70,1\% e 73,5\% nas avaliações realizadas em 2007 e 2008, respectivamente, nas tangerineiras submetidas ao raleio, enquanto no manejo convencional, no primeiro ano, obtiveram-se $49,2 \%$ e $39,5 \%$ no segundo ano (Tabela 3).

A diferença nos resultados no sistema de manejo com a adoção do raleio pode ser atribuída à obtenção de frutas de maior tamanho e a redução 
da alternância de produção, em comparação ao sistema de manejo convencional, sem a adoção do raleio, que produziu frutas de tamanho desuniforme no primeiro ano e ocorrência de alternância de produção no segundo ano. Isso demonstra que a redução significativa no número de frutas por planta compensa economicamente, por aumentar o tamanho da fruta obtida (GUARDIOLA;GARCÍALUIS, 2000) e reduzir o problema da alternância de produção.

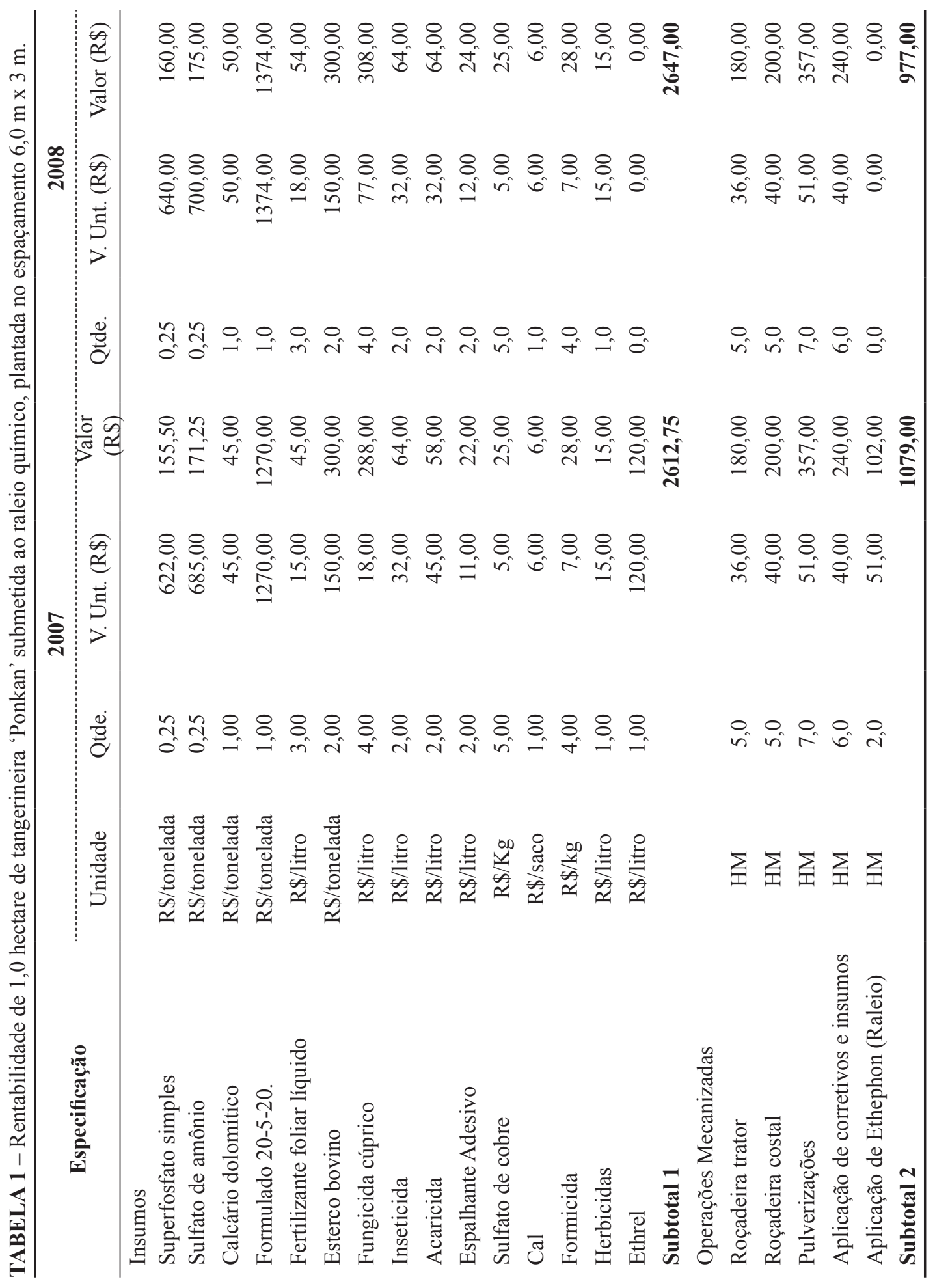




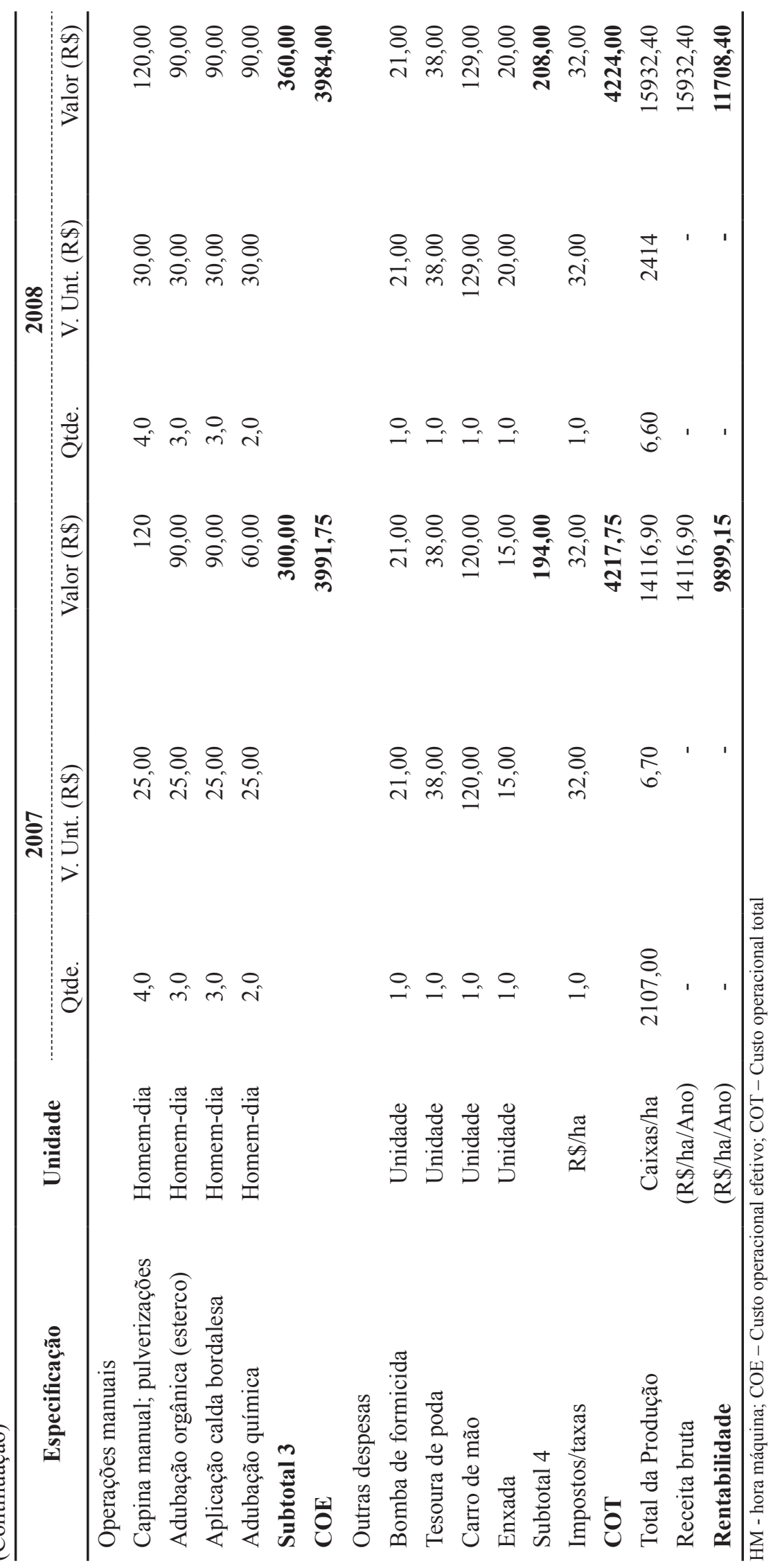




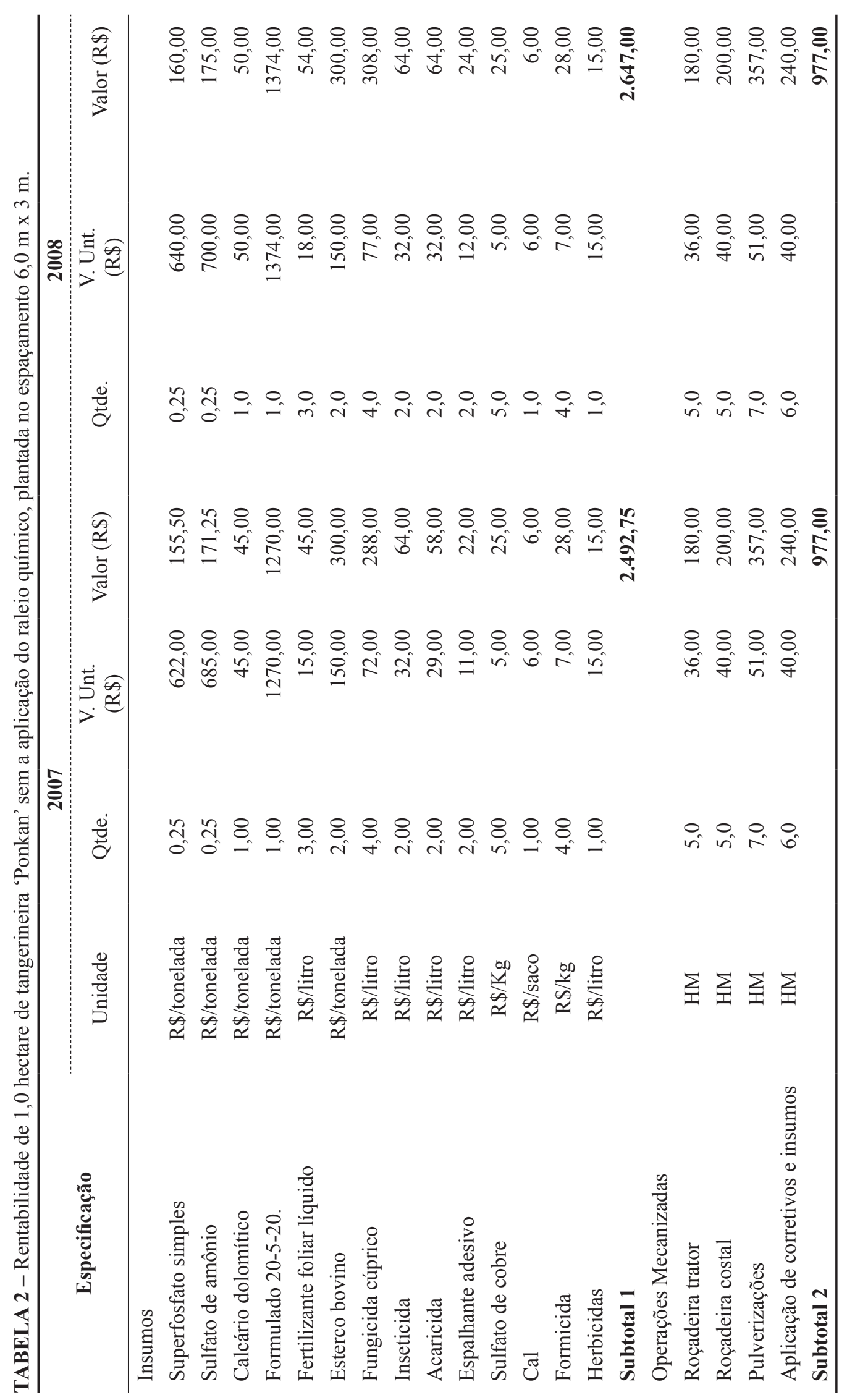




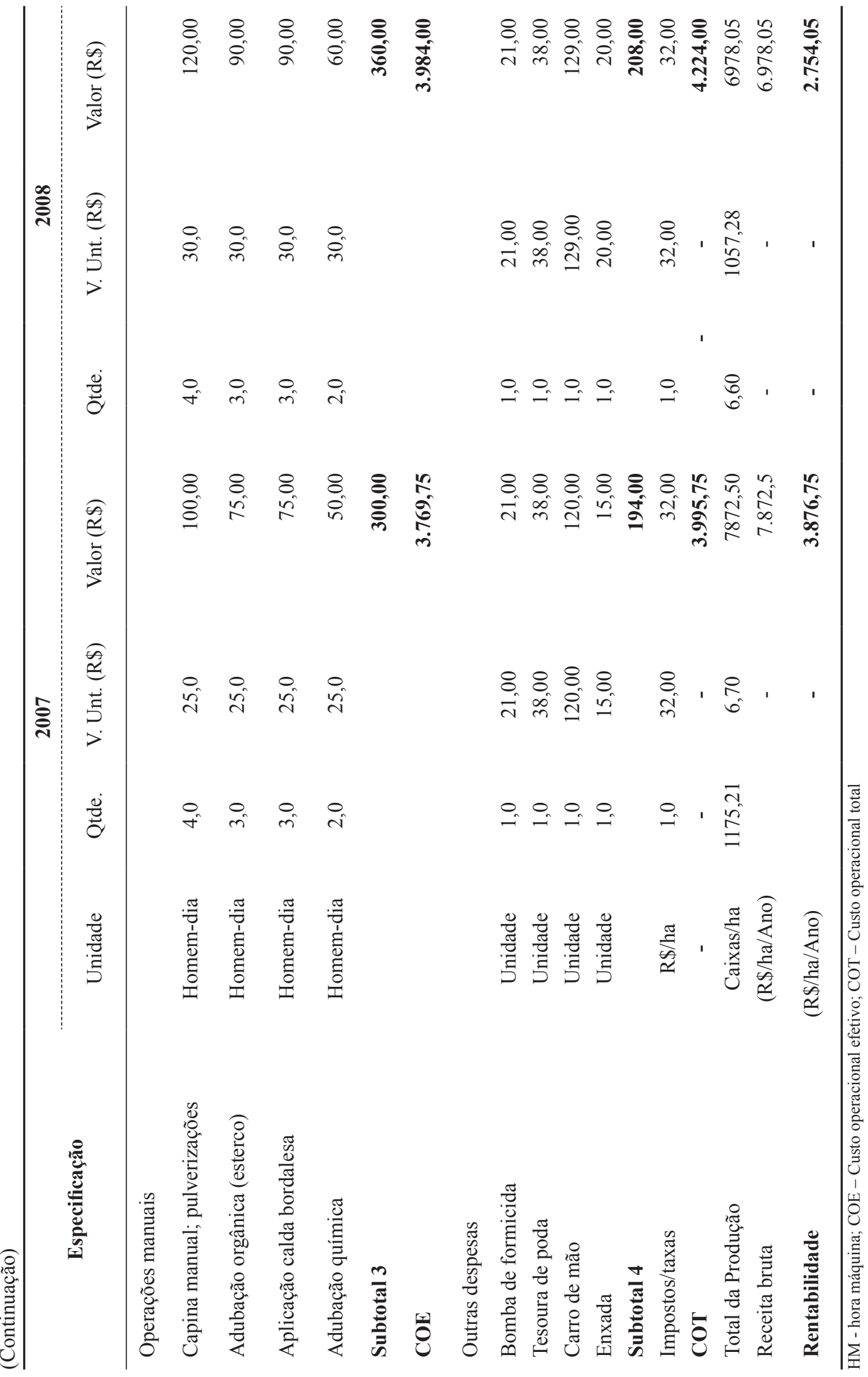


TABELA3 - Rentabilidade de 1,0 hectare de tangerineira 'Ponkan' submetida ao raleio químico e ao manejo convencional, plantada no espaçamento $6,0 \mathrm{~m}$ x $3 \mathrm{~m}$.

\begin{tabular}{lrrrr}
\hline \multirow{2}{*}{\multicolumn{1}{c}{ Descrição }} & \multicolumn{2}{c}{ Raleio químico } & \multicolumn{2}{c}{ Manejo convencional } \\
\cline { 2 - 5 } & $\mathbf{2 0 0 7}$ & $\mathbf{2 0 0 8}$ & $\mathbf{2 0 0 7}$ & $\mathbf{2 0 0 8}$ \\
\hline Preço da caixa (R\$) & 6,70 & 6,60 & 6,70 & 6,60 \\
Produtividade (caixa/ha) & 2.107 & 2.414 & 1.175 & 1.057 \\
Receita bruta (R $\$$ ha/Ano) & $14.116,90$ & $15.932,50$ & $7.872,50$ & $6.978,05$ \\
COT(R $\$$ /ha/Ano) & $4.217,50$ & $4.224,00$ & $3.995,75$ & $4.224,00$ \\
Rentabilidade (R $\$$ /ha/Ano) & $9.899,15$ & $11.708,40$ & $3.876,75$ & $2.754,05$ \\
Índice de rentabilidade (\%) & 70,1 & 73,5 & 49,2 & 39,5 \\
\hline
\end{tabular}

\section{CONCLUSÃO}

A prática do raleio químico proporcionou maior rentabilidade, em termos de produtividade da tangerina 'Ponkan', que o manejo convencional, sem a adoção do raleio.

\section{REFERÊNCIAS}

CRUZ, M.C.M.; RAMOS, J.D.; MOREIRA, R.A.; MARQUES, V.B.; VILLAR, L. Raleio químico na produção de tangerina 'Ponkan'. Revista Brasileira de Fruticultura, Jaboticabal, v.33, n.1, p.279-285, 2011.

GARCÍA-LUIS，A.; OLIVEIRA，M.E.M.; BORDÓN, Y.; SIQUEIRA, D.L.; TOMINAGA, S.; GUARDIOLA, J.L. Dry Matter Accumulation in citrus fruit is not limited by transport capacity of the pedicel. Annals of Botany, London, v.90, n. 6, p. $755-764,2002$.
GOLDSCHMIDT, E.E. Carbohydrate supply as a critical factor for citrus fruit development and productivity. HortScience, Alexandria, v. 34, p. 1020-1024, 1999.

GUARDIOLA, J. L.; GARCÍA-LUIS, A. Increase size in citrus. Thinning and stimulation of fruit growth. Plant Growth Regulation, Dordrecht, v.31, p.121-132, 2000.

MATSUNAGA, M.; BEMELMANS, P. F.; TOLEDO, P. E. N.; DULLEY, R. D.; OKAWA, H.; PEDROSO, I. A. Metodologia de custo de produção utilizada pelo IEA. Agricultura em São Paulo, São Paulo, v. 23, n. 1, p. 123-139, 1976.

PROGRAMA BRASILEIRO PARAA MELHORIA DOS PADRÕES COMERCIAIS E EMBALAGENS DE HORTIGRANJEIROS. Classificação das tangerinas. São Paulo: CEAGESP - Centro de Qualidade de Horticultura, 2000. Fôlder. 